\title{
Cytolethal Distending Toxin in Salmonella and Campylobacter spp. Isolated from Food Animals and Gastroenteritis Cases in Qatar
}

\author{
Kenlyn E. Peters ${ }^{1}$, Yu-Chen Chang ${ }^{1}$, Gerald E. Duhamel ${ }^{1}$, Ali A. Sultan ${ }^{2}$, Sanjay Doiphode ${ }^{3}$, Emad M. Ibrahim $^{3} \&$ \\ Hussni O. Mohammed ${ }^{1}$ \\ ${ }^{1}$ Cornell University, Ithaca, New York, USA \\ ${ }^{2}$ Weill Cornell Medicine Qatar, Doha, Qatar \\ ${ }^{3}$ Hamad Medical Cooperation, Doha, Qatar \\ Correspondence: Professor Hussni O. Mohammed, S1 070 Schurman Hall, College of Veterinary Medicine, \\ Cornell University, Ithaca, NY 14853, USA. Tel: 1-607-253-3566. Fax: 1-607-253-3083. E-mail: \\ hom1@cornell.edu
}

Received: June 21, 2017 Accepted: August 4, 2017 Online Published: August 16, 2017

doi:10.5539/gjhs.v9n10p34 URL: https://doi.org/10.5539/gjhs.v9n10p34

\begin{abstract}
Background: Campylobacter and Salmonella are two of the major foodborne pathogens that contribute to the burden of disease. The cytolethal distending toxin (CDT) has been identified as one of the virulence factors that may contribute to pathogenesis and gastroenteritis. The CDT is a trimeric subunit toxin produced by gram-negative bacteria that initiates cell-cycle arrest and causes affected cells to die by apoptosis. This study investigated the occurrence of CDT among Salmonella and Campylobacter spp. isolates recovered from animals along the food supply chain and from gastroenteritis cases in Qatar.
\end{abstract}

Methods: Samples were screened for the presence of the two pathogens using a combination of bacterial enrichment and molecular detection and positive samples were examined for the presence of CDT using a polymerase chain reaction (PCR) approach.

Results: $C$. jejuni and $C$. coli occurred at similar rates among non-human sources, whereas $C$. jejuni occurred at a higher rate compared to $C$. coli in human cases. Both $c d t B$ and $c d t C$ were detected at a higher rate among $C$. jejuni than $C$. coli recovered from human cases. Only $c d t B$ was detected in Salmonella spp. isolates from animals and at a much lower rate.

Conclusions: The presence of CDT in isolates recovered from gastroenteritis cases suggests a role in the pathogenesis of the condition. Furthermore, the detection of CDT among food animal isolates along the food supply chain highlights the potential zoonotic risk.

Keywords: cytolethal distending toxin; foodborne pathogens; Salmonella; Campylobacter

\section{Introduction}

Foodborne illnesses pose major health burdens worldwide. In the U.S. alone, it is estimated that 48 million people become ill due to foodborne diseases, 128,000 of those cases being hospitalized and 3,000 resulting in death (CDC, 2015). The World Health Organization (WHO) estimates that 2.2 million people worldwide die per year of diarrheal food and waterborne diseases alone (WHO, 2015). Although data on individual countries is available, information on the global burden of foodborne diseases is lacking, but estimated cost per individual nation is high (Havelaar et al., 2009; Hoffmann, Batz, \& Morris, 2012). Foodborne Diseases Burden Epidemiology Reference Group (FERG) along with WHO are currently undertaking the estimation of the worldwide burden of foodborne disease, listing Campylobacter and Salmonella spp. among the top challenges (WHO, 2015).

The risk of foodborne pathogen transmission is exacerbated by the ease of travel and the globalization of trade (Käferstein, Motarjemi, \& Bettcher, 1997). This is especially true in such international areas as Qatar, where the ratio of expatriates to natives is 9:1. Areas of such cultural diversity are key to studying foodborne illnesses. Campylobacter and Salmonella are two of the major foodborne pathogens that contribute to the burden of 
disease (Hird, Stein, Kuchenmuller, \& Green, 2009) especially in very international regions. Current detailed data on the pathogenicity of foodborne pathogens is required to mitigate the risks of transmission.

Food animals are known to be reservoirs for foodborne pathogens, therefore food products from these animals could be considered a threat to the safety of the food supply chain, putting humans at risk of contracting salmonellosis (David et al., 2013; Gorski et al., 2011; Ishihara et al., 2009; Wahlström, Andersson, Plym-Forshell, \& Pires, 2011). Perpetuation of pathogens in the environment may exacerbate the risk of salmonellosis as well from direct exposure through occupational practices (LeJeune \& Kersting, 2010; Saeed \& Hamid, 2010). Furthermore, the risk of pathogenesis in the population has been attributed to cross-contamination between meat handlers and carcasses in processing plants around the world (Gomes-Neves et al., 2012; Wamalwa, Castiello, Ombui, \& Gathuma, 2012). Knowledge of the occurrence and distribution of these pathogens along the food supply chain of animal origin is needed in order to devise cost-effective strategies to mitigate associated risks.

In addition to the immediate gastrointestinal symptoms associated with infection of these pathogens, there is the risk of chronic sequelae. The mechanisms by which these pathogens predispose hosts to these sequelae are poorly understood. Several studies hypothesize the role of CDT (cytolethal distending toxin) in the pathogenesis (Smith \& Bayles, 2006; Jindasa, Bloom, Weiss, \& Duhamel, 2011; Pokkunuri et al., 2012). However, the data remains scarce.

CDT is a bacterial toxin that initiates cell cycle arrest prior to mitosis in eukaryotic cells. It consists of three protein subunits, $\mathrm{CdtA}, \mathrm{CdtB}$, and $\mathrm{CdtC}$. CdtB is the active subunit, the other two subunits bind and deliver $\mathrm{CdtB}$ into cells. CdtB's DNase I-like activity results in DNA double-strand breaks which can cause cellular distention and arrest of the G1 and G2 phases of the cell cycle with eventual cell death by apoptosis (Smith \& Bayles, 2006; Jindasa et al., 2011). Due to these occurrences, foodborne pathogens that carry the CDT genes have been implicated in the risk of gastroenteritis as an important virulence factor. Our objectives were: 1) to investigate the presence of this gene in major foodborne pathogens isolated along the food supply chain and from gastroenteritis cases in a highly dynamic and diverse population; and 2) examine the potential correlation between the presence of the CDT among different supply chain samples and human cases.

\section{Methods}

\subsection{Target and Study Populations}

We carried out a cross-sectional study to address the stated objective. Campylobacter and Salmonella spp. were recovered from the target populations. Two populations were involved in the sampling, human and non-human. Human subjects were selected from individuals admitted to Hamad Medical Corporation hospitals in Qatar with complaints of gastroenteritis. Fecal samples were collected from the patients and tested bacteriologically for the presence of Salmonella and Campylobacter spp. These samples were collected during routine patient care. Ethical approval was granted from the Institutional Review Board for the use of these samples and patient data. The patients' backgrounds were diverse, including differing ethnicity, nationality, gender, age and diagnosis.

Non-human samples were collected along the food supply chain of animal origin. The animal sources included cattle, camels, chickens and sheep, either at dairy operations, or at abattoirs being processed for human consumption. The animal operations were located throughout the country, and the abattoirs were located in the capitol and processed all the meat supply to the market. Farms were selected randomly and sampled during both the hot (April-October) and cold (November-March) seasons. The abattoirs were also sampled during both seasons to capture potential seasonal variation and animals were selected randomly within the abattoirs. Farmers and managers were sent letters of solicitation outlining the objectives of the study and participation was voluntary.

\subsection{Sampling Procedures}

Three types of samples were collected from animals on the dairy and camel farms, including udder swabs, milk and fecal samples. Sterile gauze pads (4x4in) were used to swab the teats on the udders of individual animals and placed in sterile vials. Composite milk samples (approx. $25 \mathrm{~mL}$ from each teat) were also collected in sterile vials. Approximately $100 \mathrm{~g}$ of feces were collected per rectum using artificial insemination gloves and sterile lube and placed in plastic sterile collection containers. In addition to samples collected from the animals, environmental samples such as bedding, and water and feed trough swabs were collected. Approximately $100 \mathrm{~g}$ of bedding was collected and placed in sterile bags. Water and feed troughs were also swabbed with sterile gauze pads $(4 \times 4$ in) and placed in sterile vials.

At the abattoirs, approximately $50 \mathrm{~g}$ of feces was collected from the inside of the large intestines of slaughtered sheep and placed in sterile containers. Carcasses of sheep, cattle and camels were swabbed with sterile gauze pads in four different areas after being dressed, washed and inspected by authorities. Areas targeted were the neck, 
thorax, flank, brisket and rump. Sterile gloves were worn and changed between each sample so as to prevent cross-contamination. Four swabs were taken from chicken carcasses, two from the inside, and two from the outside, targeting the neck, breast, underwing, thigh and visceral cavity. All samples were transported to Weill Cornell Medical College of Qatar in ice boxes for processing.

\subsection{Pathogen Isolation}

\subsubsection{Human Samples}

Pathogens were isolated from human samples using standard bacteriological procedure. $1 \mathrm{~g}$ of the collected stool samples was diluted with $10 \mathrm{ml}$ of phosphate buffered saline (PBS, pH 7.2; Sigma, St. Louis, MO, USA) and 500 $\mu \mathrm{l}$ of this dilution was added to $5 \mathrm{ml}$ of Selenite broth (Oxoid, Basingstoke, Hampshire, UK) for enrichment and was incubated at $37^{\circ} \mathrm{C}$ for $24-48 \mathrm{hr}$.

Salmonella spp.- The enriched samples were subcultured onto MacConkey agar and incubated at $37{ }^{\circ} \mathrm{C}$ for $24 \mathrm{hr}$. Colonies were screened using biochemical tests such as Kilger's iron agar, motility indole-urea agar, Lysin iron agar and o-nitrophenyl- $\beta$-D-galactopyranoside. Colonies from these screenings were identified with confirmatory biochemical tests using API 20E (bioMereux, Marcy I'Etoile, France) or VITEK (bioMereux).

Campylobacter spp.- Samples were incubated on CAMP agar at $42{ }^{\circ} \mathrm{C}$ in microaerophilic conditions for the isolation of Campylobacter spp. Identification of presumptive pathogens was performed using biochemical tests and serum agglutination reactions according to standard methods.

\subsubsection{Non-human Samples}

Salmonella spp.- Non-human Salmonella samples were enriched in Tetrathionate broth (Becton, Dickinson and Company; Sparks, MD, USA) and were then spread on XLT4 agar plates (MOLTOX ${ }^{\circledR}$, Boone, NC, USA). Positive colonies of the primary enrichment media were then transferred to $500 \mu \mathrm{l}$ of BHI broth (secondary enrichment) and incubated for $24 \mathrm{hr}$ at $37^{\circ} \mathrm{C}$.

Campylobacter spp.- The primary enrichment consisted of BHI supplemented with Cefoperazone $(6 \mathrm{mg} / \mathrm{L})$, Vancomycin $(6 \mathrm{mg} / \mathrm{L})$, and Amphotericin B $(2 \mathrm{mg} / \mathrm{L})$. The primary enrichment was inoculated with the samples and incubated at $37^{\circ} \mathrm{C}$ for $24 \mathrm{hr}$. The secondary enrichment also was BHI and was also incubated at $37{ }^{\circ} \mathrm{C}$ for 24 hr.

\subsection{PCR Detection}

PCR detection was performed to determine pathogen presence using the BAX® Automated System (Dupont, USA). A $5 \mu \mathrm{l}$ aliquot of the respective secondary enrichment (BHI or MEC broth) was added to $200 \mu \mathrm{l}$ of the buffer (proteinase-containing lysis buffer) provided by the manufacturer. Samples were then heated in the lysis reagent solution to rupture the bacterial cell wall and release the DNA. PCR tablets, which contain all the reagents necessary for PCR plus fluorescent dye, were hydrated with the lysed sample and processed in the cycler/detector provided by the manufacturer. Within a few hours, the polymerase chain reaction (PCR) amplified a DNA fragment specific to the target. The amplified DNA generates a fluorescent signal, which the BAX ${ }^{\circledR}$ system application uses to analyze the findings. Results are displayed on a monitor screen as simple positive or negative symbols.

\subsection{CDT Detection}

Genomic DNA was then extracted from the pure cultures following the MasterPure DNA purification kit (Epicenter Biotechnologies, Madison, WI, USA). Then PCR amplification and gel electrophoresis were utilized to determine the presence of the genes for CDT subunits among the samples. CdtB was the primary subunit tested for due to it being the active subunit (Smith \& Bayles, 2006; Jindasa et al., 2011). The CDT genes were detected in Campylobacter samples using the Takara Campylobacter Detection Kit (Takara Bio Inc., Japan). Primers used for $c d t B$ detection in Salmonella samples were; Forward: 5'-tgcagctatatttctttgcetgcg-3' and Reverse: 5'-acagcttcgtgccaaaaaggc-3'.

\subsection{Statistical Analysis}

The population specific prevalence of these pathogens was computed as the proportion that tested positive out of all samples that were tested within each population. The prevalence of CDT within each pathogen and among different populations was computed as the proportion that tested positive for $c d t$ genes out of all the samples that tested positive for the particular pathogens. The significance of differences in the prevalence of the pathogens between humans and non-human, and the prevalence of CDT among isolates from the two populations was evaluated using the student-test. The odds of a particular pathogen within each population was evaluated using 
logistic regression and quantified using the odds ratio (OR). The significance of association of both pathogens in a particular sample from non-human sources was evaluated using the McNemar chi-square test. All statistical tests were performed using the SPSS v.23 (IBM-statistical software, White Plains, NY) and P-values were evaluated at $\mathrm{P}<0.05$.

\section{Results}

Salmonella spp. was present in 159 out of 1128 non-human samples (14\%) and in 402 out of 776 human samples $(52 \%)$. There was a significant difference in the prevalence of Salmonella spp. between the two populations. The odds were about 7 times greater to isolate Salmonella spp. from humans in comparison to non-humans (Table 1). Campylobacter was present in 155 out of 1128 non-human samples (14\%) and 177 out of 776 human samples $(23 \%)$. The odds were about two times greater to detect Campylobacter spp. among gastroenteritis cases in comparison to non-human sources (Table 1).

Table 1. The significance of association of the distribution of the pathogens in the study between human and non-human sources.

\begin{tabular}{llll}
\hline Source & Positive & Negative & $\begin{array}{l}\text { Odds ratio and }(95 \% \text { Confidence } \\
\text { Interval) }\end{array}$ \\
\hline $\begin{array}{c}\text { Salmonella } \text { spp. } \\
\text { Human }\end{array}$ & 402 & 374 & \\
Non-human & 159 & 969 & $6.6(5.3,8.2)$ \\
Campylobacter spp. & & & \\
Human & 177 & 599 & $1.9(1.5,2.4)$ \\
Non-human & 155 & 973 & \\
\hline
\end{tabular}

Table 2. The odds of Campylobacter spp. within each source (human and non-human) as computed using the McNemar's chi-square test.

\begin{tabular}{|c|c|c|c|c|c|}
\hline \multirow[t]{2}{*}{ Source } & & \multicolumn{2}{|c|}{ C. coli } & \multirow{2}{*}{$\begin{array}{l}\text { Odds ratio and } \\
95 \% \mathrm{CI}\end{array}$} & \multirow[t]{2}{*}{ Kappa statistics } \\
\hline & & Positive & Negative & & \\
\hline \multicolumn{6}{|l|}{ Human } \\
\hline C. jejuni & Positive & 10 & 127 & & \\
\hline & Negative & 32 & 8 & $4.0(2.7,6.0)$ & 0 \\
\hline \multicolumn{6}{|l|}{ Non-human } \\
\hline C. jejuni & Positive & 40 & 58 & & \\
\hline & Negative & 56 & 1 & $1.0(0.7,1.5)$ & 0 \\
\hline
\end{tabular}


Table 3. The significance of association of the distribution of Campylobacter spp. in the study between human and non-human sources

\begin{tabular}{lllllll}
\hline Source & $\begin{array}{l}\text { C. jejuni } \\
\text { positive }\end{array}$ & $\begin{array}{l}\text { C. jejuni } \\
\text { positive }\end{array}$ & $\begin{array}{l}\text { Odds ratio } \\
\text { and } 95 \% \text { CI }\end{array}$ & C. coli positive & C. coli positive & $\begin{array}{l}\text { Odds ratio and } \\
95 \% \text { CI }\end{array}$ \\
\hline Human & 137 & 40 & & 42 & 135 & \\
Non-human & 96 & 59 & 98 & 37 & Inverse $=5.5$ \\
& & & $2.1(1.3,3.4)$ & & $(3.4,8.9)$ \\
\hline
\end{tabular}

Table 4. The association between $c d t B$ and $c d t C$ in Campylobacter spp. isolated from each source as computed using the McNemar's chi-square test

\begin{tabular}{llll}
\hline Source & $c d t C$ & Negative & $\begin{array}{l}\text { Odds ratio and Kappa statistics } \\
95 \% \mathrm{CI}\end{array}$ \\
& Positive & & \\
\hline
\end{tabular}

\section{Human C. jejuni}

$c d t B$

Positive $\quad 99$

$\begin{array}{lllll}\text { Negative } & 12 & 47 & 1.6(0.7,3.6) & 0.6\end{array}$

Human C. coli

$c d t B$

Positive $\quad 31 \quad 8$

Negative $3 \quad 135$

$135 \quad 2.7(0.6,15.6) \quad 0.8$

Non-human C. jejuni

$c d t B$

Positive $\quad 41 \quad 11$

0.8

Non-human C. coli

$c d t B$

$\begin{array}{lllll}\text { Positive } & 66 & 17 & & \\ \text { Negative } & 13 & 61 & 1.3(0.6,2.9) & 0.6\end{array}$

Within the non-human samples there was no significant difference in the prevalence of Salmonella in comparison to Campylobacter (both 14\%). We also evaluated the odds of pathogens, Campylobacter spp. and Salmonella spp. occurring in samples collected from non-human sources using the McNemar chi-square test. A total of 30 samples had both pathogens and there was no significant association which indicates that the occurrence of both pathogens was random.

C. jejuni was more common among the human isolates in comparison to C. coli (77 vs. $24 \%$ ) (Figure 1). C. lari was not detected among the samples collected from humans. The odds were 4 times greater to isolate $C$. jejuni from gastroenteritis cases compared to $C$. coli $(\mathrm{OR}=4.0)$ (Table 2). Both $C$. jejuni and $C$. coli occurred at an equal proportion among non-human samples (62 and 63\%) (Figure 1). The odds of $C$. jejuni occurrence was two times greater in samples collected from gastroenteritis cases compared to samples from non-human sources (OR $=2.1$ ) (Table 3). On the other hand, the odds were about six times greater to detect $C$. coli in samples from non-human sources in comparison to gastroenteritis cases $(\mathrm{OR}=5.5)$ (Table 3). Neither of the pathogens were isolated from the same case of gastroenteritis. 
$100 \%$

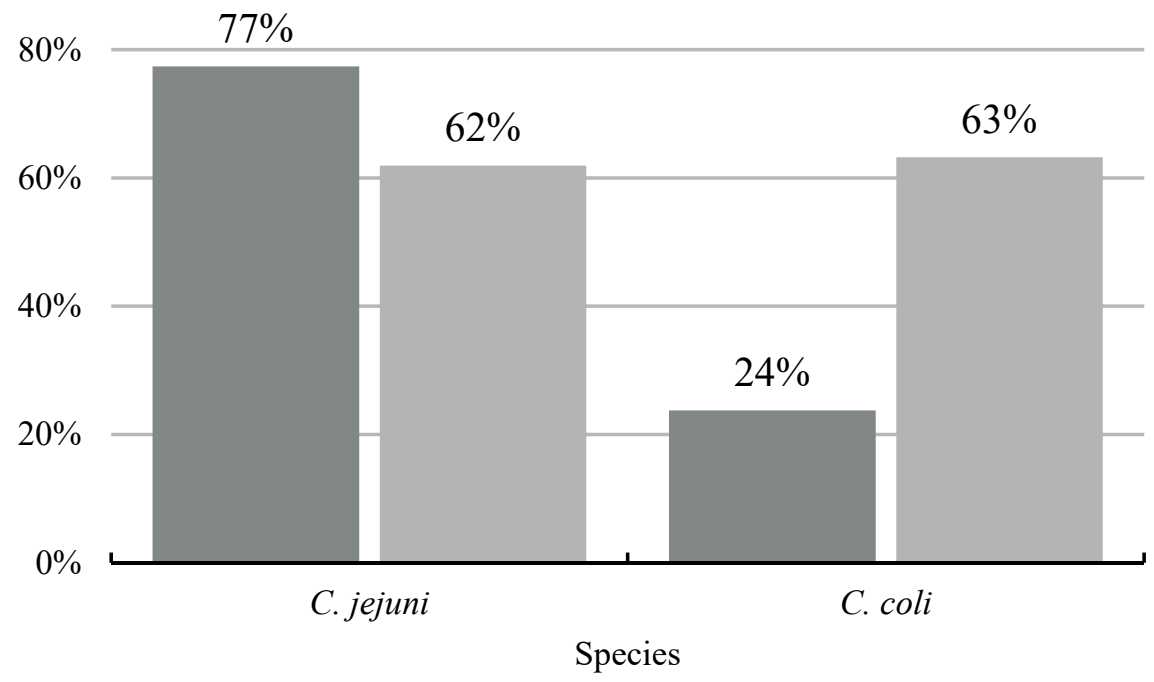

- Human

von-human

Figure 1. Prevalence of Campylobacter spp. in samples along the food supply chain of animal origin and in cases of gastroenteritis in the target populations

Among the Campylobacter spp. isolates from non-human sources, 96 were $C$. jejuni and 98 were C. coli. The $c d t B$ gene was more common among the $C$. coli isolates in comparison to $C$. jejuni isolates (54 vs. $29 \%$ ), occurrence of the $c d t C$ gene was similar (51 vs. 34\%) (Figure 2). Table 4 shows the significance of the concurrent occurrence of $c d t B$ and $c d t C$ in Campylobacter spp. isolated from each source. The kappa statistics demonstrate they are likely pathogenic due to the occurrence of both genes (Table 4).

$100 \%$

$80 \%$

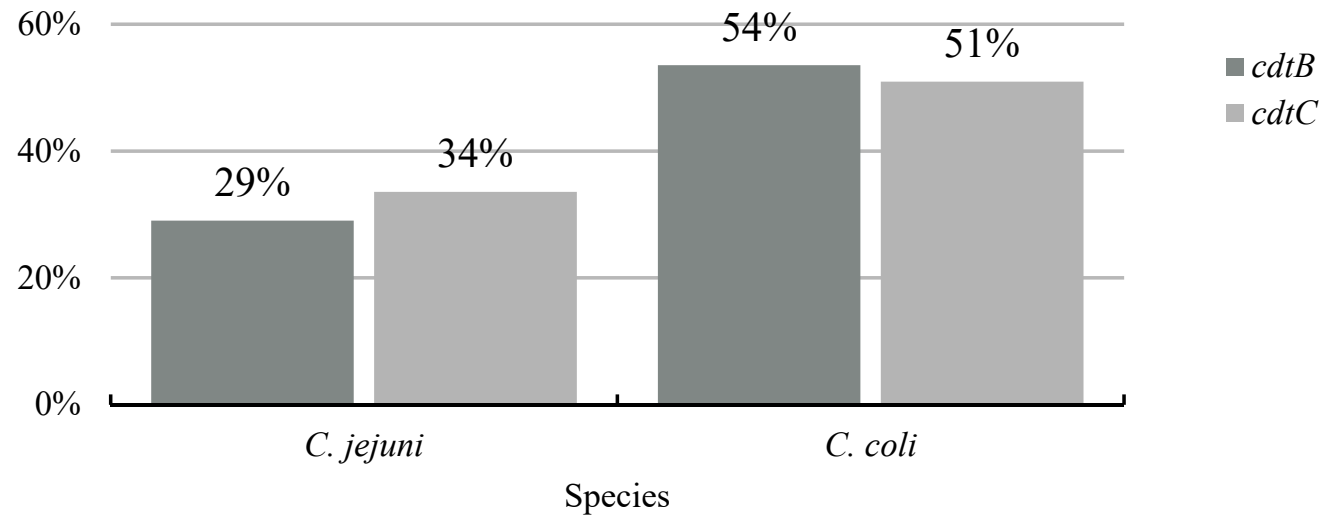

Figure 2. The proportion of samples with $c d t B$ and $c d t C$ among $C$. jejuni and $C$. coli isolates recovered from the food supply chain (non-human) in the target population.

The distribution of $c d t B$ and $c d t C$ among the human isolates of $C$. jejuni and $C$. coli are shown in Figure 3. These two genes are about three times more common among the $C$. jejuni than $C$. coli isolates and were detected at a relatively similar proportion within each species (Figure 3). The majority of $C$. jejuni from humans had both 
genes and there was significant agreement in their occurrence beyond chance $(k a p p a=0.6)$ (Table 4). Although the two genes were detected at a lower rate among the $C$. coli isolates in comparison to $C$. jejuni, there was significant agreement in the occurrence of the $c d t B$ and $c d t C$ among the $C$. coli isolates ( $k a p p a=0.8$ ) (Table 4).

Only $c d t B$ was detected in Salmonella spp. animal samples and at a much lower proportion (3\%) in comparison to its proportion among the Campylobacter isolates. Similarly, the $c d t B$ gene was detected at a lower proportion among the Salmonella spp isolates from human samples (5\%).

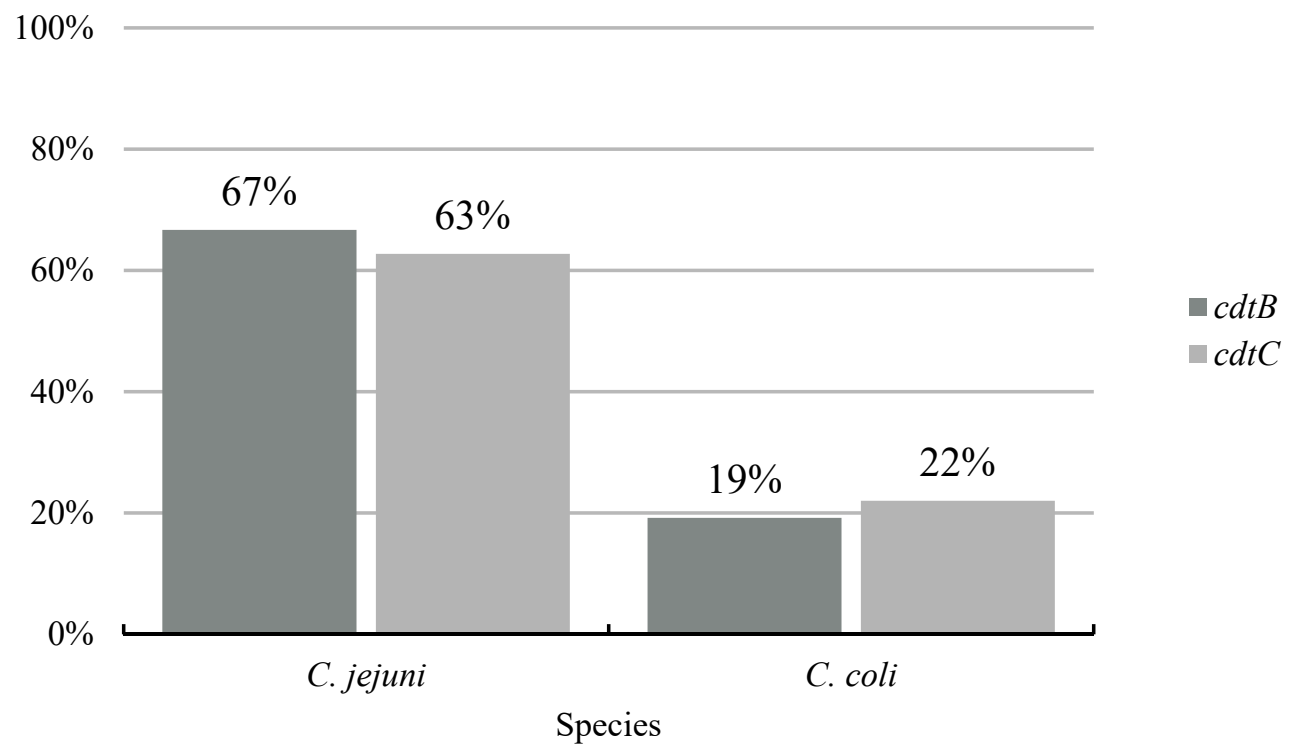

Figure 3. The proportion of samples with $c d t B$ and $c d t C$ among $C$. jejuni and $C$. coli isolates recovered from cases of gastroenteritis (human) in the target population

\section{Discussion}

The overall objectives of the current study were to shed light on the mechanisms by which foodborne pathogens predispose people to the risk of illness by identifying possible pathogenic agents. The study focused on two major foodborne pathogens, Campylobacter and Salmonella spp. and the possible role of CDT in pathogenesis. Foodborne pathogens have been incriminated in the risk of gastroenteritis and the mechanism of disease is currently not fully understood (Hird et al., 2009). The two foodborne pathogens investigated in this study are among the common pathogens that pose significant burden of disease around the world (WHO, 2015); Havelaar et al., 2012; Hoffmann et al., 2012). Gastroenteritis infections caused by these two pathogens are mostly self-limiting and admissions to hospitals are not common. In a few cases, around 6-7\%, patients with gastrointestinal illness may develop sequelae with serious consequences (Hoffmann et al., 2012). Many factors could play roles in exacerbating the risk of gastroenteritis including CDT (Smith \& Bayles, 2006; Pokkunuri et al., 2012).

We used a multidisciplinary epidemiological approach to investigate the occurrence of these foodborne pathogens in diverse populations (non-humans and humans) and determined the presence of the CDT among the pathogens in order to shed light on one of the putative mechanisms of pathogenicity (Smith \& Bayles, 2006; Pokkunuri et al., 2012). Qatar was chosen due to its diverse social and cultural population which includes diverse food and methods of food preparation. Because of this diversity, we would expect to see diverse pathogens and mechanisms of disease. The more knowledge gained on mechanisms of pathogenicity would greatly aid in mitigating the risk of these pathogens.

We examined the occurrence of these two foodborne pathogens among two populations, humans and animals. To our knowledge this is the first study that attempted to investigate these pathogens in human and animal populations in the same geographic area (LeJeune \& Kersting, 2010). Other studies examine the risk of transmission of these pathogens between animals and humans among certain sectors, food handlers or processors (Saeed \& Hamid, 2010; Gomes-Neves et al., 2012). Our study showed that both pathogens occur at relatively high proportions in samples collected from gastroenteritis cases and from the food supply chain of animal origin. 
The data also hinted at the potential of transmission of the two pathogens through the food supply chain to human hosts. The investigation was a cross-sectional study where samples were collected from the sources at one point of time and it is difficult to extrapolate the directionality of the transmission. The rationale for the apparent higher occurrence of the pathogens among humans in this study could be explained by the fact that all the samples were collected from patients admitted to the hospital with the complaint of gastroenteritis, a condition associated with Campylobacter and Salmonella spp. infections.

Although CDT is known as one of the virulence factors that plays a role in the pathogenicity of Campylobacter spp., the exact mechanism by which gastroenteritis develops is poorly understood. Most of the published research has focused on the method in which CDT affects cells and not proportion of infection. It has been suggested that differences in the protein subunits $c d t A$ and $c d t C$ could influence which types of cells CDT affects, so while CDT is not specific to different types of bacteria, it may be affected by cell specificity which could explain differing pathogenicity among hosts (Smith \& Bayles, 2006; Jindasa et al., 2011). In this study, the association between the presence of both $c d t B$ and $c d t C$ among gastroenteritis cases was investigated and we found that both subunits were detected in $84 \%$ of $C$. jejuni and $79 \%$ of $C$. coli cases with CDT genes. In comparison to Mortensen's et al. study, we were able to detect both subunits of the CDT in a lesser, but not significantly different, proportion (Mortensen et al., 2011). However, the role of the CDT in the pathogenesis of gastroenteritis is not fully understood. By virtue of its toxicity, CDT has been incriminated in the risk of chronic gastroenteritis sequelae, including Inflammatory Bowel Disease as shown in studies on rats (Pokkunuri et al., 2012). CDT has the ability to attack the cells of intestinal villi, which allows normal bacterial biota to enter and cause infection.

One of our objectives was to shed light on the correlation in the occurrence of these foodborne pathogens and the CDT genes in the food supply chain of animal origin and in cases of gastroenteritis in humans. The intent was to evaluate this correlation at the population level and examine whether the rate of occurrence of the CDT gene for these pathogens was similar among isolates from the two populations. The rationale was to explore whether the food supply chain of animal origin has the potential to predispose humans to the risk of gastroenteritis and whether we could identify points of intervention along the chain. We are not familiar with studies that have attempted to address a similar objective. One study examined the occurrence of the CDT genes in Campylobacter spp. from animal and human sources, however it was not clear if the isolates were collected at the same time (Findik et al., 2011). Acik, Karahan, Ongor and Cetinkaya (2013) examined the prevalence of the $c d t B$ and $c d t C$ in samples of C. jejuni and C. coli recovered from sheep and reported a similar proportional occurrence of this virulence factor as observed in our study. Other studies observed convenient samples of isolates or single species (Dipineto et al., 2001; Ge, Schauer, \& Fox, 2008; Band et al., 2001) and some specifically looked at strains known to carry CDT genes (Pickett et al., 2003; Pickett et al., 1996). Reports of Campylobacter prevalence are similar to our findings, C. jejuni prevalence was much higher than $C$. coli (Dipineto et al., 2001; Band et al., 2001), though these studies were solely in regards to chickens. We also sampled multiple species of animals, some not previously reported. Work has been done on the different variations of CDT production by different strains of E. coli (Pickett et al., 2003; Tóth, Hérault, Beutin, \& Oswald, 2003) and extensive work has been done on Campylobacter (Dipineto et al., 2001; Band et al., 2001; Pickett et al., 1996; Eyigor, Dawson, Langlois, \& Pickett, 1999), but little data is present on Salmonella.

\section{Conclusion}

The high prevalence of the $c d t$ genes among Campylobacter isolates, especially $C$. jejuni in human gastroenteritis cases $(c d t B: 67 \%, c d t C: 63 \%)$ points to a critical role as a virulence factor in the pathogenesis of the condition. The concurrent occurrence of this virulence factor $(c d t B$ and $c d t C)$ among isolates from the food supply chain of animal origin indicates that these food sources pose a risk to humans in terms of gastroenteritis and its sequelae. In spite of the fact that the Campylobacter spp. isolates had a similar rate of occurrence of the genes as gastroenteritis cases, none of the live animals showed any clinical signs of disease. By virtue of its toxicity, CDT has been incriminated in the risk of chronic gastroenteritis sequelae, including Inflammatory Bowel Disease and Inflammatory Bowel Syndrome as shown in studies on rats (Pokkunuri et al., 2012). Knowledge gained on the occurrence of these foodborne pathogens in the food supply system and the presence of the virulence factor could be used to introduce intervention strategies to mitigate their associated risk.

\section{Acknowledgements}

This research is supported by grants from Qatar National Research Funds; grant numbers NPRP 08-465-4-009, NPRP 7-292-3-070. 


\section{Competing Interests Statement}

The authors declare that there are no competing or potential conflicts of interest.

\section{References}

Acik, M. N., Karahan, M., Ongor, H., \& Cetinkaya, B. (2013). Investigation of virulence and cytolethal distending toxin genes in Campylobacter spp. isolated from sheep in Turkey. Foodborne Pathogens and Disease, 10(7), 589-94. https://doi.org/10.1089/fpd.2012.1447

Band, D. D., Scheutz, F., Ahrens, P., Pederson, K., Blom, J., \& Madsen, M. (2001). Prevalence of cytolethal distending toxin (cdt) genes and CDT production in Campylobacter spp. isolated from Danish broilers. Journal of Medical Microbiology, 50, 1087-1094. https://doi.org/10.1099/0022-1317-50-12-1087

Centers for Disease Control and Prevention. (2014). Estimates of Foodborne Disease in the United States. Centers for Disease Control and Prevention. Retrieved January 25, 2016, from http://www.cdc.gov/foodborneburden/

David, J. M., Sanders, P., Bemrah, N., Granier, S. A., Denis, M., Weill, F. X., ... Watier, L. (2013). Attribution of the French human Salmonellosis cases to the main food-sources according to the type of surveillance data. Preventive Veterinary Medicine, 110(1), 12-27. https://doi.org/10.1016/j.prevetmed.2013.02.002

Dipineto, L., Gargiulo, A., Russo, T. P., De Luca Bossa, L. M., Borrelli, L., Menna, L. F., \& Fioretti, A. (2011). Campylobacter jejuni, Campylobacter coli, and Cytolethal Distending Toxin Genes in Laying Hens. Avian Diseases, 55, 103-105. https://doi.org/10.1637/9525-091510-ResNote.1

Eyigor, A., Dawson, K. A., Langlois, B. E., \& Pickett, C. L. (1999). Cytolethal Distending Toxin Genes in Campylobacter jejuni and Campylobacter coli Isolates: Detection and Analysis by PCR. Journal of Clinical Microbiology, 37, 1646-1650.

Findik, A., Ica, T., Onuk, E. E., Percin, D., Kevenk, T. O., \& Ciftci, A. (2011). Molecular typing and cdt genes prevalence of Campylobacter jejuni isolates from various sources. Tropical Animal Health and Production, 43(3), 711-9. https://doi.org/10.1007/s11250-010-9758-0

Ge, Z., Schauer, D. B., \& Fox, J. G. (2008). In vivo virulence properties of bacterial cytolethal-distending toxin. Cellular Microbiology, 10, 1599-1697. https://doi.org/10.1111/j.1462-5822.2008.01173.x

Gomes-Neves, E., Antunes, P., Tavares, A., Themudo, P., Cardoso, M. F., Gärtner, F., ... Peixe, L. (2012). Salmonella cross-contamination in swine abattoirs in Portugal: Carcasses, meat and meat handlers. International Journal of Food Microbiology, 157(1), 82-7. https://doi.org/10.1016/j.ijfoodmicro.2012.04.015

Gorski, L., Parker, C. T., Liang, A., Cooley, M. B., Jay-Russell, M. T., Gordus, A. G., ... Mandrell, R. E. (2011). Prevalence, distribution, and diversity of Salmonella enterica in a major produce region of California. Applied Environmental Microbiology, 77(8), 2734-48. https://doi.org/10.1128/AEM.02321-10

Havelaar, A. H., Haagsma, J. A., Mangen, M. J., Kemmeren, J. M., Verhoef, L. P., Vijgen, S. M., ... van Pelt, W. (2012). Disease burden of foodborne pathogens in the Netherlands, 2009. International Journal of Food Microbiology, 156, 231-238. https://doi.org/10.1016/j.ijfoodmicro.2012.03.029

Hird, S., Stein, C., Kuchenmuller, T., \& Green, R. (2009). Meeting report: Second annual meeting of the World Health Organization initiative to estimate the global burden of foodborne diseases. International Journal of Food Microbiology, 133, 210-212. https://doi.org/10.1016/j.ijfoodmicro.2009.05.028

Hoffmann, S., Batz, M. B., \& Morris, J. G., Jr., (2012). Annual cost of illness and quality-adjusted life year losses in the United States due to 14 foodborne pathogens. Journal of Food Protection, 75, 1292-1302. https://doi.org/10.4315/0362-028X.JFP-11-417

Käferstein, F. K., Motarjemi, Y., \& Bettcher, D. W. (1997). Foodborne disease control: a transnational challenge. Emerging Infectious Diseases, 3(4), 503-510. https://doi.org/10.3201/eid0304.970414

Ishihara, K., Takahashi, T., Morioka, A., Kojima, A., Kijima, M., Asai, T., \& Tamura, Y. (2009). National surveillance of Salmonella enterica in food-producing animals in Japan. Acta Veterinaria Scandinavica, 51, 35. https://doi.org/10.1186/1751-0147-51-35

Jinadasa, R. N., Bloom, S. E., Weiss, R. S., \& Duhamel, G. E. (2011). Cytolethal distending toxin: a conserved bacterial genotoxin that blocks cell cycle progression, leading to apoptosis of a broad range of mammalian cell lineages. Microbiology, 157(Pt 7), 1851-75. https://doi.org/10.1099/mic.0.049536-0

LeJeune, J., \& Kersting, A. (2010). Zoonoses: an occupational hazard for livestock workers and a public health concern for rural communities. Journal of Agricultural Safety and Health, 16(3), 161-79. 
https://doi.org/10.13031/2013.32041

Mortensen, N. P., Schiellerup, P., Boisen, N., Klein, B. M., Locht, H., Abuoun, M., ... Krogfelt, K. A. (2011). The role of Campylobacter jejuni cytolethal distending toxin in gastroenteritis: toxin detection, antibody production, and clinical outcome. APMIS, 119, 626-634. https://doi.org/10.1111/j.1600-0463.2011.02781.x

Pickett, C. L., Pesci, E. C., Cottle, D. L., Russel, G., Erdem, A. N., \& Zeytin, H. (1996). Prevalence of Cytolethal Distending Toxin Production in Campylobacter jejuni and Relatedness of Campylobacter sp, cdtB Genes. Infection and Immunity, 64, 2070-2078.

Pickett, C. L., Lee, R. B., Eyigor, A., Elitzur, B., Fox, E. M., \& Strockbine, N. A. (2003). Patterns of Variations in Escherichia coli Strains That Produce Cytolethal Distending Toxin. Infection and Immunity, 72, 684-690. https://doi.org/10.1128/IAI.72.2.684-690.2004

Pokkunuri, V., Pimentel, M., Morales, W., Jee, S. R., Alpern, J., Weitsman, S., ... Chang, C. (2012). Role of Cytolethal Distending Toxin in Altered Stool Form and Bowel Phenotypes in a Rat Model of Post-infectious Irritable Bowel Syndrome. Journal of Neurogastroenterology and Motility, 18(4), 434-42. https://doi.org/10.5056/jnm.2012.18.4.434

Saeed, H. A., \& Hamid, H. H. (2010). Bacteriological and parasitological assessment of food handlers in the Omdurman area of Sudan. Journal of Microbiology, Immunology and Infection, 43(1), 70-3. https://doi.org/10.1016/S1684-1182(10)60010-2

Smith, J. L., \& Bayles, D. O. (2006). The Contribution of Cytolethal Distending Toxin to Bacterial Pathogenesis. Critical Reviews in Microbiology, 32, 227-248. https://doi.org/10.1080/10408410601023557

Tóth, I., Hérault, F., Beutin, L., \& Oswald, E. (2003). Production of Cytolethal Distending Toxins by Pathogenic Escherichia coli Strains Isolated from Human and Animal Sources: Establishment of the Existence of a New cdt Variant (Type IV). Journal of Clinical Microbiology, 41, 4285-4291. https://doi.org/10.1128/JCM.41.9.4285-4291.2003

Wahlström, H., Andersson, Y., Plym-Forshell, L., \& Pires, S. M. (2011). Source attribution of human Salmonella cases in Sweden. Epidemiology and Infection, 139(8), 1246-53. https://doi.org/10.1017/S0950268810002293

Wamalwa, K., Castiello, M., Ombui, J. N., Gathuma, J. (2012). Capacity building: benchmark for production of meat with low levels of bacterial contamination in local slaughterhouses in Somaliland. Tropical Animal Health and Production, 44(3), 427-33. https://doi.org/10.1007/s11250-011-9914-1

World Health Organization. (2015). Food safety: Global burden of foodborne diseases. Retrieved January 25, 2016, from http://www.who.int/foodsafety/areas_work/foodborne-diseases

\section{Copyrights}

Copyright for this article is retained by the author(s), with first publication rights granted to the journal.

This is an open-access article distributed under the terms and conditions of the Creative Commons Attribution license (http://creativecommons.org/licenses/by/4.0/). 